\title{
KONSEP SYAFAAT \\ DALAM RENCANA TOTAL ALLAH
}

\section{Mesakh Jasmin}

\section{Abstrak}

Secara teknis, syafaat sesungguhnya bukanlah doa. Doa syafaat adalah doa. Tetapi syafaat adalah sesuatu yang dilakukan seseorang dalam doa. Syafaat adalah berdoa berdasarkan apa yang telah Yesus lakukan, yaitu berdasarkan karya penebusan yang telah dilakukan Yesus

\section{Pendahuluan}

Dalam Rencana Total Allah, tidak ada suatu peristiwa yang terjadi diluar dari ketetapan Allah. Allah berdaulat penuh terhadap seluruh ciptaan-Nya dan Ia mengizinkan segala sesuatu terjadi di muka bumi sebagai bagian dari tindakan pemeliharaan-Nya.

Rencana Allah terutama berkaitan dengan apa yang dilakukan oleh Allah sendiri yaitu mencipta, memelihara, memimpin dan menebus. Rencana Allah juga melibatkan kehendak dan tindakan manusia, namun hanya bersifat sekunder yaitu, sebagai sarana untuk mencapai apa yang telah direncanakan oleh Allah. Peranan Allah di sini ialah memutuskan agar hal-hal tertentu terjadi dalam kehidupan manusia dan bukan memberikan perintah untuk bertindak dengan cara tertentu. Apa yang Allah putuskan untuk terjadi memang memerlukan unsur keharusan. Tetapi fakta-fakta dari rencana Allah sebaiknya tidak dianggap sebagai perintah, tapi lebih sebagai uraian tentang apa yang akan terjadi. Rencana Allah tidak memaksa manusia untuk bertindak dengan cara tertentu, tapi membuat manusia pasti secara bebas bertindak menurut cara-cara itu. Jadi, walaupun Rencana Total Allah itu berkaitan terutama dengan dengan apa yang dilakukan oleh Allah, tindakan-tindakan manusia juga tercakup di dalamnya.

Rencana dan tindakan manusia akan menghasilkan penggenapan maksud Allah (Amsal 16:1 ; 19:21). Tindakan manusia ini sebagai sarana, dalam hal ini sebagai wakil dan pengantara yang "menghadirkan" uraian rencana Allah. Nyata dari Alkitab bahwa Allah dalam banyak hal Allah bekerja dalam semacam kemitraan dengan manusia. Allah tidak bertindak bila manusia tidak memainkan peranannya. Peranan manusia dalam hal ini adalah Syafaat (tindakan dalam doa). Doa bukanlah memaksakan Allah melakukan kehendak manusia, tetapi suatu sikap melalui mana manusia ingin agar kehendak Allah terjadi. Oleh sebab itu, Penulis akan membahas mengenai konsep syafaat ini dalam sebuah karya ilmiah yang diberi judul "Konsep Syafaat Dalam Rencana Total Allah."

\section{Batasan Penulisan}

Berbicara mengenai konsep syafaat dalam Rencana Total Allah adalah hal yang sangat luas. Dalam tulisan ini, Penulis akan membahas konsep syafaat dalam konteks penciptaan manusia, kejatuhan manusia dan karya penebusan Yesus Kristus. 


\section{Pokok Masalah}

Dalam usaha mengkaji konsep syafaat pada setiap konteks seperti di atas, Penulis akan membahas: Apakah arti syafaat itu? Apakah kebutuhan terbesar manusia sejak kejatuhannya? Kalau providensia ada, mengapa perlu berdoa? Bagaimana dengan peperangan rohani? Apakah orang Kristen punya otoritas atas iblis?

Penulis menyadari bahwa tulisan ini tidak memuat seluruh jawaban Alkitabiah yang ada. Tetapi tulisan ini merupakan jawaban-jawaban yang dianggap penulis sebagai sebuah pengertian yang jelas mengenai syafaat dalam Alkitab sebatas kemampuan analisa penulis.

\section{KONSEP SYAFAAT}

\section{Pengertian Istilah}

Istilah syafaat dalam bahasa inggris adalah "Intercession" yang artinya permohonan untuk orang lain dan perantaraan. Websters mengartikan Intercession sebagai: "act of interceding; mediation; interposition between parties at varience, with a view reconciliation; prayer; petition or entreaty in favour of" (tindakan mengantarai; perantaraan; mencampuri dua pihak dengan tujuan mendamaikan; doa; permohonan atau permohonan atas nama). ${ }^{1}$

Jadi, dari istilah "Intercession" dapat disimpulkan bahwa, Syafaat adalah tindakan mengantarai atau menengahi yang Penulis istilahkan dengan sebuah tindakan "menghadirkan kembali." Untuk memahami ini lebih jelas, Penulis akan membahasnya dalam tiga konteks sebagai berikut:

\section{RENCANA ALLAH BAGI MANUSIA PADA WAKTU PENCIPTAAN}

Pada waktu Allah menciptakan manusia, yaitu Adam, Ia menciptakan manusia serupa dan segambar dengan diri-Nya dengan tujuan memberikan kepadanya kuasa untuk memerintah seluruh bumi. Dengan kata lain Adam adalah wakil Allah di dunia. Kata "mewakili seseorang" dalam bahasa Inggris adalah "representation". Webster mendefinisikannya sebagai "to present again"(menyajikan, memperkenalkan, atau menghadirkan kembali). ${ }^{2}$ Jadi, wakil adalah seseorang yang menghadirkan kembali kehendak orang yang diwakilinya.

\section{Serupa dan Segambar dengan Allah}

Manusia serupa dan segambar dengan Allah berarti bahwa manusia memiliki kesamaan dengan Allah. Kesamaan ini terdapat dalam kesamaan mental (Kej.2:15-20; Kol.3:10), kesamaan moral (Pkh.7:9; Hab.1:13; Efs. 4:24), dan kesamaan sosial (Kej.3:8). Ketiga kesamaan ini tidak dapat dihapus karena memungkinkan manusia bersekutu dengan Allah dan memperoleh penebusan.

Di dalam kebudayaan Timur Tengah adakalanya raja mengangkat orang-orang menjadi "gambarnya" di daerah-daerah tertentu. Artinya tokoh-tokoh itu harus melakukan kekuasaan di daerah itu atas nama raja. Mereka adalah kuasa raja. Merekalah yang memegang mandat dan 
menjadi wakil. ${ }^{3}$ Jadi, pembahasan bahwa Allah menciptakan manusia menurut gambar-Nya berkaitan erat dengan tugas yang segera disusulkan, yaitu manusia mendapat panggilan untuk menguasai bumi.

\section{Kemuliaan Manusia}

Adam ditugaskan untuk memelihara bumi. Kata "memelihara" dalam bahasa Ibrani adalah "Shamar"_yang berarti menjaga atau melindungi. ${ }^{4}$ Secara harafiah, Adam ditugaskan Allah menjadi penjaga atau pemelihara bumi. Jadi, Allah tidak menyerahkan kepemilikan atas bumi, tetapi memberikan tanggung jawab (otoritas, hak) untuk mengaturnya kepada manusia. Inilah kemuliaan manusia, yaitu manusia adalah mahkluk yang bertanggung jawab.

\section{KEGAGALAN MANUSIA MENGGENAPI RENCANA ALLAH}

Manusia bisa jatuh ke dalam dosa karena kesempurnaan dan kekudusan manusia adalah kesempurnaan dan kekudusan yang "belum diteguhkan." Maksudnya adalah bahwa kesempurnaan dan kekudusan manusia baru merupakan sifat yang sempurna dan kudus, belum diperkuat menjadi watak yang sempurna dan kudus.

\section{Kejatuhan Manusia Dalam Dosa}

Manusia menyinarkan kemuliaan Allah (1 Kor.11:7). Bahasa Yunani untuk "kemuliaan" adalah "doksa", artinya: keindahan, kuasa yang mulia, kebanggaan. ${ }^{5}$ Kuasa yang mulia (doksa) yang diterima Adam untuk memerintah bumi sangat sempurna dan utuh sehingga ia, tidak hanya Allah, mampu memberikan kuasa yang mulia yaitu tanggung jawab (otoritas) itu kepada orang lain. Adam memberikan otoritas itu kepada iblis saat ia jatuh ke dalam dosa. Hal ini terbukti ketika iblis mencobai Yesus (Luk. 4:6), ia berkata: "segala kuasa (eksousia) serta kemuliaannya (doksa) akan kuberikan kepada-Mu, sebab semuanya itu telah diserahkan kepadaku, dan aku memberikannya kepada siapa saja yang ku kehendaki."

\section{Kebutuhan Manusia}

Pada hakikatnya, manusia membutuhkan dua hal penting sejak kejatuhannya. Manusia membutuhkan seseorang yang dapat menjadi perantara untuk mendamaikan manusia dengan Allah. Manusia juga memerlukan seseorang yang dapat menjadi perantara untuk memisahkan manusia dari iblis. Hal pertama mengenai penyatuan dan yang kedua mengenai pemisahan. Karya perantaraan Kristus merupakan karya dwi fungsi, yaitu mendamaikan dan memisahkan. Itu berarti Kristus adalah satu-satunya perantara bagi manusia dan Allah (1 Tim.2:5).

\section{SOLUSI ALLAH: \\ KARYA PENEBUSAN YESUS KRISTUS}

Adam telah gagal dalam menjalankan tugasnya, sehingga Allah mengutus "Adam Terakhir" untuk melakukan apa yang seharusnya dilakukan Adam pertama dan memperbaiki apa yang telah dirusakannya. 


\section{Syafaat: Menanggung Beban}

Karya perantaraan Kristus mencapai pernyataanya secara penuh dan menyeluruh manakala dosa-dosa manusia "ditimpakan" kepada-Nya dan Dia "menanggung” serta menyingkirkannya. Yesaya 53 merupakan salah satu nubuatan PL tentang salib kristus yang paling jelas.

Yesaya 53:6,12 berkata:

TUHAN telah menimpakan kepadanya kejahatan kita sekalian ... ia menanggung dosa banyak orang dan berdoa untuk pemberontak pemberontak. Bahasa ibrani syafaat, yaitu PAGA dipakai dua kali dalam ayat-ayat ini. PAGA diterjemahkan sebagai "ditimpakan" (KJV: Lay) dan "berdoa" (KJV: Intercession). ${ }^{6}$ Kata pasif "ditimpakan akan menimbulkan kata kerja aktif "menanggung." Menanggung dalam bahasa Ibrani adalah "nasa" artinya memikul pergi atau memindahkan jauh-jauh. ${ }^{7}$ Dalam bahasa Yunani kata "menanggung" adalah "bastazo" yang berarti mengangkat, membawa, menanggung, memikul, memindahkan, menahan (penderitaan). ${ }^{8}$ Beberapa ayat yang memakai kata ini adalah sebagai berikut:

Matius 8:17. Dialah yang memikul kelemahan kita dan menanggung (bastazo) penyakit kita.

Roma 5:1. Kita yang kuat wajib menanggung (bastazo) kelemahan orang yang tidak kuat.

Galatia 6:2. Bertolong-tolonglah menanggung (bastazo) bebanmu!

Dari beberapa penjelasan di atas, dapat ditarik kesimpulan bahwa syafaat adalah sebuah tindakan menanggung beban orang lain dan membawa pergi beban itu sama seperti yang dilakukan Yesus. Tetapi tidak berarti secara harafiah melakukan kembali apa yang telah dilakukan Yesus, melainkan menghadirkan kembali apa yang telah dilakukan-Nya.

\section{Syafaat: Sebuah Perjumpaan}

Konsep yang lain mengenai syafaat adalah "berjumpa." Syafaat (perantaraan). Menciptakan sebuah perjumpaan. Telah dijelaskan sebelumnya, bahwa manusia memiliki dua kebutuhan, yaitu "didamaikan" dan "dipisahkan." Kedua hal ini menciptakan dua perjumpaan, yaitu "perjumpaan pendamaian" dan "perjumpaan kekerasan."

1. Perjumpaan Pendamaian

Alkitab menggambarkan apa yang telah dilakukan Yesus saat Ia berjumpa dengan Allah Bapa untuk menciptakan sebuah perjumpaan antara Allah dan manusia, yaitu perjumpaan pendamaian. Pelayanan pendamaian Kristus digenapi di kayu salib dimana kasih dan keadilan-Nya bertemu (Maz. 85:11). Pelayanan pendamaian yang sudah dikerjakan Yesus, dipercayakan kepada manusia ( 2 Kor. 5:18-20). Dari sini dapat ditarik kesimpulan, bahwa syafaat adalah penerusan pelayanan pendamaian yang telah dikerjakan Yesus melalui karya penebusan-Nya.

2. Perjumpaan yang Keras

Syafaat (PAGA) kadangkala memiliki konotasi yang sangat keras. PAGA seringkali dipakai sebagai istilah pertempuran (Hak. 8:21; 1 Sam 22:17). ${ }^{10}$ Jadi syafaat dapat menjadi suatu perjumpaan yang keras yang sering di istilahkan sebagai Peperangan Rohani.

Arthur Matthew mengatakan "Kemenangan di Kalvari itu adalah fakta yang telah terjadi, tetapi harus ada manusia yang mengambil erat kemenangan itu dan mencetuskan peperangan dengan musuh serta melawannya."11 Jadi, tujuan peperangan rohani bukanlah untuk mengalahkan iblis, karena ia telah dikalahkan. Tetapi tujuan peperangan rohani adalah menghadirkan kembali kuasa kemenangan salib Kristus. Peperangan rohani tetap diperlukan walaupun Kristus telah mengalahkan 
iblis, karena kehancuran iblis bukanlah kehancuran secara harafiah, melainkan kehancuran secara legal atas kepemimpinan dan otoritasnya. Terdapat perbedaan antara otoritas dan kuasa. Otoritas adalah hak untuk mempengaruhi atau mengendalikan, sedangkan kuasa adalah kemampuan untuk melaksanakan kemauan. ${ }^{12}$ Alkitab tidak pernah mengatakan bahwa Kristus membebaskan manusia dari kuasa iblis (kemampuan untuk mengendalikan dan mempengaruhi manusia). Tetapi Alkitab mengatakan bahwa, Yesus membebaskan manusia dari otoritas iblis, yaitu haknya untuk menggunakan kuasanya atas manusia.

Kolose 1:13, Ia telah melepaskan kita dari kuasa (eksousia) kegelapan

Lukas 10:19, Sesungguhnya aku telah memberikan kuasa (eksousia).

Bahasa Yunani "eksousia" berarti: hak, pengontrolan. ${ }^{13}$ Jadi jelas bahwa kuasa tidak akan pernah menjadi masalah antara Allah dengan iblis. Yang menjadi masalah adalah otoritas, yaitu otoritas yang dirampas iblis dari Adam. Yesus tidak datang untuk merebut kuasa (kemampuan) itu dan memusnahkan iblis. Tetapi Ia datang untuk mendapatkan kembali otoritas yang diberikan Adam kepada iblis serta menghancurkan kepemimpinan iblis di bumi.

Iblis masih memiliki kuasa serta kemampuannya (1 Pet. 5:8; Efs. 6:6), tetapi sekarang iblis tidak memiliki hak (otoritas) lagi untuk menggunakannya atas orang yang menjadikan Yesus Tuhan mereka. Iblis dapat memakai kuasa atau kemampuannya untuk menghancurkan manusia yang tidak mengerti bahwa melalui Kristus, manusia telah diberi otoritas atas iblis dan kuasanya. Otoritas penting sekali. Kuasa yang mengerjakan pekerjaan itu, tapi otoritaslah yang mengatur kuasa itu.

\section{APLIKASI KONSEP SYAFAAT DALAM DOA SYAFAAT}

\section{Alasan Pentingnya Berdoa}

1. Tanggung jawab

Dalam konteks penciptaan, manusia diciptakan segambar dengan Allah. Kesamaan ini memungkinkan manusia bersekutu dengan Allah. Manusia juga diberikan kemuliaan, yaitu sebagai mahkluk yang bertanggung jawab. Hubungan kedua hal ini dalam aplikasinya adalah: manusia dapat bersekutu dengan Allah melalui tanggung jawabnya, yaitu berdoa.

2. Allah bekerja melalui manusia

Allah harus menjadi manusia karena Ia memilih untuk bekerja melalui manusia. Dari sini dapat dilihat alasan pentingnya berdoa. Yaitu Allah memilih sejak penciptaan untuk bekerja melalui manusia (Yak. 5:16).

3. Membangun batas perlindungan

Dalam Yosua 19, kata PAGA dipakai beberapa kali. Dalam konteks ini PAGA diterjemahkan sebagai "menyinggung dan "batas." The Spirit Filled Bible mengatakan bahwa PAGA, jika dipakai dalam konteks ini berarti "The extent to which a boundary reaches" (perluasan yang dapat dicapai oleh sebuah pembatasan). ${ }^{14}$ Ini adalah hal yang logis, karena memang garis-garis batas dapat dihubungkan dengan doa. Ini berarti manusia dapat membangun garis-garis batas perlindungan di sekeliling dirinya dan orang lain melalui doa. Doa ini merupakan sebuah tanggung jawab. Alkitab dipenuhi dengan prinsip-prinsip yang membutuhkan tanggung jawab manusia. tanggung jawab ini menjadi syarat menerima janji perlindungan Tuhan. Dalam Mazmur 91:1 versi KJV bila diterjemahkan sebagai berikut: "Orang yang berdiam dalam lindungan Yang 
Maha Tinggi akan tinggal dalam naungan Yang Maha Kuasa." Kata "lindungan" (secret place) disamakan Yesus dengan “tempat tesembunyi”(secret place) dalam Matius 6:6 yang adalah "kamar doa."15 Dari sini dapat ditarik kesimpulan bahwa, perlindungan tidak diterima secara otomatis. Meskipun manusia menerima janji perlindungan, manusia tetap memiliki peranan penting dalam hal meraih perlindungan itu bagi dirinya sendiri, maupun bagi orang lain melalui doa.

\section{Arti Berdoa Dalam Nama-Nya}

Menurut Yohanes 1:18, Yesus menyatakan Allah kepada manusia. Tetapi tindakan Yesus "menyatakan Bapa" bukanlah satu-satunya tujuan karya perantaraan-Nya. Kristus telah menjadi wakil Allah. Ia tidak hanya mewakili Allah dihadapan manusia tetapi juga mewakili manusia dihadapan Allah. Dialah Rasul (Allah bagi umat manusia) dan Imam Besar (umat manusia kepada Allah) yang diakui (Ibrani 3:1). Dari sini dapat diketahui bahwa syafaat (tindakan menengahi) Kristus bukanlah doa yang Ia doakan, tetapi karya perantaraan yang telah dilakukan-Nya (Yohanes 6:26). Jadi, jelas bahwa Yesus tidak berdoa bagi manusia. Tetapi Ia menjadi perantara bagi manusia melalui karya penebusan-Nya sehingga manusia dapat berdoa. Inilah arti berdoa di dalam nama-Nya.

\section{Waktu Berdoa}

Efesus 6:18 yang adalah konteks peperangan rohani mengatakan: "berdoalah setiap waktu dalam Roh." Kata "waktu" dalam konteks ini adalah "kairos"(yunani), yang artinya: waktu yang strategis atau waktu yang tepat. ${ }^{16}$ Maksudnya, waktu (kesempatan) yang baik dimana sesuatu harus dilakukan saat itu juga. Jadi, dapat disimpulkan bahwa, manusia harus berjaga-jaga terhadap serangan iblis yang terencana untuk dapat menciptakan batas-batas perlindungan melalui berdoa pada waktu yang tepat.

\section{KESIMPULAN}

Pada mulanya, syafaat adalah sebuah tindakan mewakili Allah. Kemudian konsep syafaat berkembang menjadi tindakan mewakili atau menjadi perantara untuk mendamaikan manusia dengan Allah dan memisahkan manusia dari iblis. Syafaat sudah dilakukan dan digenapi oleh kristus dalam karya penebusan-Nya. Oleh sebab itu, sekarang syafaat adalah sebuah tindakan dalam doa, yaitu berdoa berdasarkan karya penebusan yang telah dilakukan-Nya . Doa syafaat yang merupakan aplikasi dari konsep syafaat hanyalah sebuah perluasan atau perpanjangan dari apa yang telah dilakukan Kristus. Perluasan atau perpanjangan ini dapat dilakukan karena pelayanan pendamaian yang sudah dikerjakan Yesus, dipercayakan kepada manusia (2 Kor.5:18-20) serta penyerahan kembali otoritas atas bumi dan ciptaan-Nya kepada manusia (Luk. 10:19). Jadi, ketika manusia berdoa, bersyafaat, atau melakukan peperangan rohani, ia melakukannya dalam posisi sudah menang (karena Yesus sudah menang) dan bukan merebut kemenangan, tetapi menghadirkan kembali kemenangan yang telah dikerjakan Yesus di Kalvari. Inilah inti dari syafaat. 


\section{Endnotes:}

${ }^{1}$ Webster's, New International Dictionary of English language, 1124.

${ }^{2}$ Ibid, 1809.

${ }^{3}$ J. Verkuyl, Etika Kristen Bagian Umum, (Jakarta: BPK Gunung Mulia, 2004), 34.

${ }^{4}$ Dutch Sheets, Doa Syafaat, (Jakarta: Imanuel, 1999), 30.

${ }^{5}$ Hasan Sutanto, Perjanjian Baru Interlinear dan Konkordansi (PBIK), (Jakarta: LAI, 2004), ref. D-255.

${ }^{6}$ James Strong, The New Strong's - Exhaustive Concordance of the Bible, ref. no. 6293.

${ }^{7}$ Dutch Sheets, Doa Syafaat, (Jakarta: Imanuel, 1990), 69.

${ }^{8}$ Hasan Sutanto, PBIK, ref. B-44.

${ }^{9}$ Strong, The New Exhaustive Concordance, ref. no. 6293.

${ }^{10}$ Ibid.

${ }^{11}$ R. Arthur Matthew, Born For Battle, (Robesonia: OMF Books, 1978), 106.

${ }^{12}$ Ide diambil dari catatan Ilmu Sosial Dasar, Dosen: Pdt. Ivan Weisman.

${ }^{13}$ Hasan Sutanto, PBIK, ref. E-404.

${ }^{14}$ Dutch Sheets, Doa Syafaat, (Jakarta: Imanuel, 1990), 83.

${ }^{15}$ Robert. H. Schuller, Possibility Thinkers Bible (KJV), (Thomas Nelson Publishers, 1984).

${ }^{16}$ Hasan Sutanto, PBIK, ref. K-37.

\section{KEPUSTAKAAN}

Alkitab, Jakarta: Lembaga Alkitab Indonesia, 1996.

Strong, James, The New Strong's - Exhaustive Concordance of the Bible, Nashville: Thomas Nelson Publishers, 1990.

Webster's, New International of English Language, USA: Published by Merriam Company, 1915.

Schuller, Robert, King James Version Possibility Thinkers Bible, Nashville: Thomas Nelson Publishers, 1984.

Sutanto, Hasan, Perjanjian Baru Interlinear dan Konkordansi (PBIK), Jakarta: Lembaga Alkitab Indonesia, 2004.

Verkuyl. J, Etika Kristen Bagian Umum, Jakarta: BPK Gunung Mulia, 2004.

Sheets, Dutch, Doa Syafaat, Jakarta: Imanuel, 1999.

Echols, John, Shaidly, Hasan, Kamus Inggris-Indonesia, Jakarta: PT Gramedia, 2000.

Matthews, R, Arthur, Born For Battle, USA: Published by OMF Books, 1978. 